\title{
How exchange rate affects Chinese processing trade? The case of
}

\section{ground fish}

Dengjun Zhang*

University of Stavanger, N-4030, Stavanger, Norway

Email: dengjun.zhang@uis.no

*Corresponding author

Jinghua Xie

School of Business and Economics, The Arctic University of Norway / UiT, Norway.

Email: jinghua.xie@uit.no

Øystein Myrland

School of Business and Economics, The Arctic University of Norway / UiT, Norway.

Email: oystein.myrland@uit.no

\begin{abstract}
As imports destined for primary processing and then exporting occur across industries, in this study we developed a structural model to examine how exchange rate affects the exports of processed ground fish from China. The home demand for processed goods is incorporated into the model in accordance with the fact that the share of processed goods remaining in China tends to increase over time. China is the world's largest import-processing center of ground fish. The fact that China produces almost no ground fish facilitates identifying the trade data. For exports with both foreign and domestic origins, the data issue is a big challenge for empirical studies. The simulated results indicate that a 7\% appreciation of the Chinese currency would raise the export price of processed ground fish by $4.06 \%$, corresponding to a share of $40 \%$ foreign content in the processed product. In addition, the increased share of home consumption would enlarge the responses of exports to changes in the exchange rate.
\end{abstract}


Keywords: exchange rage, trade, China, ground fish, processing

Reference to this paper

Biographical notes: Dengjun Zhang is Associated Professor in the Business School at the University of Stavanger. He holds a Ph.D. in Applied Economics from Auburn University, USA. His research fields cover price and volatility transmission, trade effect of volatility, and profitability, with case studies on fisheries, energy, and finance.

Jinghua Xie is an Associate Professor at School of Business and Economics, UiT_The Arctic University of Norway. Her research interest is in the field of applied economics, with a primary research focus on seafood market and fisheries.

Øystein Myrland is a Professor at School of Business and Economics, The Arctic University of Norway/UiT. His research interests are in the field of market analysis, i.e. price analysis and advertising evaluation, using econometric and partial equilibrium models.

1 


\section{Introduction}

China's penetration in the global market have been widely explored in the literature, in terms of trade policies (Wang, 2003; Zhang et al., 2011), the Chinese undervalued currency (Wang et al., 2007; BAAK, 2008; Cheung et al., 2010; Zhang and Kinnucan, 2014), low-cost labour (Schott, 2008; Álvarez and Claro, 2009; Yang et al., 2010), and price advantages (Zhang and Zheng, 2016). In a labor-abundant country like China, imports used as raw materials for processing appear across industries (Zhang and Gan, 2007; Koopman et al., 2008). The processed product trade plays a crucial role in the Chinese economy and accounts for a substantial share of trade surpluses $(\mathrm{Xu}$ and $\mathrm{Lu}$, 2009; Manova and Zhang, 2012). In this situation, empirical studies should allow for interactions between exports and imports when examining the determinants of China's penetration in the global trade. An additional complication is that some final products made from the imported raw materials remain in the domestic market. This should affect the impacts of changes in the determinants on Chinese exports of processed goods.

Take the exchange rate as an example. The undervalued currency is widely thought to be the root cause of China's huge trade surpluses. American and European policy makers insist that appreciation of the Chinese currency will undercut the competitiveness of Chinese products and consequently reduce the huge imbalances in the bilateral trade with China. However, this could be overstated if a large share of China's exports is made from the raw materials originating from foreign countries. As reported in the media (The New York Times, 2010), “A stronger renminbi, however, would affect only the portion of the work done in China." On the other hand, appreciation of the Chinese currency is expected to cause a surge in the demand for tradable goods. For processing trade, this means fewer 
final goods exported to the world. This would strengthen the impact of the exchange rate on exports, as more processed goods with foreign content are consumed in China than in the world market. As Rodrik (2010) puts it, "Neither exports nor trade surpluses are key as long as domestic demand for tradables can be increased along with the domestic supply.' Thus, it is imperative to analyze Chinese exports in a broader context.

The purpose of this paper is to explore how exchange rate and home consumption affect the trade of processed products from China, with a case study of ground fish. We first derive a structural model and allow for interactions and feedback effects between export demand, domestic demand, and import supply of raw materials. The fully specified model facilitates a better understanding of the connections between the raw material market and the two final markets. The simulation conducted after the model further permits to quantify the consequences of changes in determinants for exports. The empirical model is applied to the Chinese ground fish trade. Ground fish includes cod, pollock, and haddock and is an important group for China's fish processing industry.

The growth of China's seafood ${ }^{1}$ trade has been hugely explosive since the 1990s (Zhang et al., 2014). From 2000 to 2010, the total Chinese seafood exports in terms of value surged by $470 \%$, alongside $340 \%$ growth in seafood imports (FAO, 2012). In 2011, China exported seafood products amounting to US\$10.1 billion, which accounted for $10 \%$ of the global seafood trade flows (FAO, 2012). Regarding origins of China's seafood exports, Li and Huang (2005) report that $60 \%$ of the seafood imported by China was used as raw material for exports in 2002. For a particular species like ground fish,

\footnotetext{
${ }^{1}$ In this paper, "seafood" is used as a synonym for fish and fishery products inclusive of capture fisheries and aquaculture products as well as freshwater products.
} 
around $70 \%$ of imports are in the form of raw fish used for further processing (Xie, 2012).

The trade data from different sources do not report whether the exported products are based on imported raw materials or not. This makes it difficult to distinguish between imports for exporting and those for domestic consumption. Since China mainly imports fresh and frozen whole fish to process into frozen fillets and export, one rough index to reveal the trend of exports is relative volumes between imported and exported fresh and frozen whole fishery products. According to Food and Agricultural Organization of the United Nations' (FAO) FishStatJ, in 2010, 69\% of Chinese imports of fish and fishery products were in the form of fresh and frozen whole fish. Meanwhile, the counterpart for exports was $11 \%$. Looking back to 2000 , the indices were $53 \%$ for imports and $10 \%$ for exports. The large volume of the imported whole fisheries products coincides with the great share of the processed products exported, implying a large amount of processed good exports.

Ground fish is an important fish group with respect to Chinese seafood trade as a whole and particularly its processing trade. In the primary destination markets (the EU, the US, and Japan), $20 \%$ of ground fish products are from China. ${ }^{2}$ The main species of ground fish, like cod, pollock, and haddock, are not cultured or are little harvested in China. The trade data show that more than $90 \%$ of these ground fish products are imported from Russia, the US, and Norway, and are processed as frozen fillets in the Qingdao area of China and then exported to the US and the EU markets.

\footnotetext{
${ }^{2}$ We rely on data from the major partner countries (the EU, the US, and Japan) for the analysis. The same data are used to construct the time series for the variables appearing in the regression equations.
} 
The paper is structured as follows. We begin with the derivation of the structural model, which is followed by a comparative analysis in section 3 . In section 4, we estimate the demand and supply equations for the empirical case. In section 5 , the reduced-form elasticities to measure the individual and combined effects of the determinants are derived and the total effects are simulated. To produce more reliable results, we also test the sensitivity of the simulation results. The paper concludes with a summary of the key findings and implications.

\section{Methodology}

In a general case, raw materials imported by China can be consumed domestically or processed into final products for exports. The export demand depends on the export price and global economic activities. Similarly, the domestic demand is determined by the domestic price and domestic economic activities. On the supply side, the price and capacity of exports are the main forces driving raw materials exported by foreign suppliers. With the foregoing assumptions, the basic model is represented by:

$$
\begin{array}{ll}
Q_{1}=D^{1}\left(P_{1}^{*}, Y^{*}\right) & \text { (Export Demand) } \\
Q_{2}=D^{2}\left(P_{2}, Y\right) & \text { (Domestic Demand) } \\
Q_{3}=S^{3}\left(P_{3}^{*}, A^{*}\right) & \text { (Import Supply) }
\end{array}
$$

where $D$ and $S$ are the demand and supply functions, respectively; $P$ is the price and the asterisk denotes that is expressed in a foreign currency; $Y$ is the economic activity and the asterisk shows that it is at the world level; and $A^{*}$ is foreign countries' production capacity of raw materials, which are exported to China for deep processing. In general, in these equations, notations with 1 are related to the demand for the final products in other 
countries, notations with 2 are related to the domestic demand for the final products, notations with 3 are related to the supply of raw materials from other countries, and the notations with * are variables that work in the trade markets (export demand and import supply).

For both exported and domestically consumed products with imports as raw materials, the input-output coefficients are assumed to be constant, indicating a Leontief technology. This means that raw materials and processing work are combined in fixed proportions to produce the final products for the foreign or domestic markets. This yields the quantity identity:

$$
Q_{3}=\mu_{1} Q_{1}+\mu_{2} Q_{2} \quad \text { (Quantity identity) }
$$

where $\mu$ is the dressing percentage, i.e. the physical units of raw material needed to produce one unit of the processed product. ${ }^{3}$ If we assume that the final products exported are more processed than those remaining in the domestic market, we have $\mu_{1}>\mu_{2}$.

The system is closed by price linkages: ${ }^{4}$

$$
\begin{array}{ll}
P_{1}^{*}={ }_{1} P_{3}^{*}+C_{1} \times R & \text { (Price Linkage I) } \\
P_{2}={ }_{2} P_{3}^{*} / R+C_{2} & \text { (Price Linkage II) }
\end{array}
$$

where $R$ is the exchange rate expressed as the price of foreign currency per China's currency; $C_{1}$ and $C_{2}$ are unit processing costs of the exported and domestically consumed products, respectively.

\footnotetext{
${ }^{3}$ Here, $\mu$ is related to the processing technique, which is assumed to be constant during the sample period (see Amiti and Freund, 2010).

${ }^{4}$ The export and import prices may be expressed with different bilateral exchange rates. In this research, we focus on the percentage changes in exogenous variables like the exchange rate. Given the integration between exchange rates, the same percentage changes in the bilateral exchange rates are not unreasonable.
} 
The structural model as defined by equations (1)-(6) allows for interactions and feedback effects between the raw material market and the two final markets. Specifically, the quantity identity equation (4) connects the material market to the two upward markets, while the price linkage equations (5) and (6) reveal the interactions between the raw material market and the upward consumption markets.

In terms of percentage changes (i.e. for any variable $X, \hat{X}=\frac{X}{X}$ ), the equation system (1)-(6) is restated as:

$$
\begin{aligned}
& \hat{Q}_{1}={ }_{11} \hat{P}_{1}^{*}+{ }_{1 Y^{*}} \hat{Y}^{*} \\
& \hat{Q}_{2}={ }_{22} \hat{P}_{2}+{ }_{2 Y} \hat{Y} \\
& \hat{Q}_{3}={ }_{33} \hat{P}_{3}^{*}+{ }_{3 A^{*}} \hat{A}^{*} \\
& \hat{Q}_{3}=k_{1}{ }_{1} \hat{Q}_{1}+k_{2}{ }_{2} \hat{Q}_{2} \\
& \hat{P}_{1}^{*}=f_{1} \hat{P}_{3}^{*}+h_{1}\left(\hat{C}_{1}+\hat{R}\right) \\
& \hat{P}_{2}=f_{2}\left(\hat{P}_{3}^{*} \quad \hat{R}\right)+h_{2} \hat{C}_{2}
\end{aligned}
$$

where $\eta$ and $\varepsilon$ denote the demand and supply elasticities, respectively; $k$ is the ratio of the volume of exports (or domestically consumed products) to the volume of the total imports; and $f$ and $h$ are the price transmission elasticities. Here $f_{1}$ and $h_{1}$ actually stand for the 'foreign content' and 'home content' of exported products, respectively, since $f_{1}=\frac{u P_{3}^{*}}{P_{1}}$ and $h_{1}=\frac{C_{1} \times R}{P_{1}}$. It is worth pointing out that $f_{1}+h_{1}=1$ according to the price linkage, i.e. equation (5). Similarly, $f_{2}$ and $h_{2}$ are the "foreign content' and "home content' of domestically consumed goods; $f_{2}+h_{2}=1$. 
Equations (7)-(12) belong to the class of equilibrium displacement models (EDM), which are widely used in the literature for trade policy analysis (Kinnucan and Myrland, 2005; Dhoubhadel et al., 2015; Luckstead and Devadoss, 2016). The main virtue is the easy with which the comparative-statistic analysis can be conducted. For our case, the system contains six endogenous variables $\left(\hat{Q}_{1}, \hat{Q}_{2}, \hat{Q}_{3}, \hat{P}_{1}^{*}, \hat{P}_{2}, \hat{P}_{3}^{*}\right)$ and six exogenous variables $\left(\hat{Y}^{*}, \hat{Y}, \hat{C}_{1}, \hat{C}_{2}, \hat{R}, \hat{A}^{*}\right)$. The system in matrix form is:

$\begin{array}{cccccccccccccc}1 & 0 & 0 & 11 & 0 & 0 & \hat{Q}_{1} & 1 Y^{*} & 0 & 0 & 0 & 0 & 0 & \hat{Y}^{*} \\ 0 & 1 & 0 & 0 & 22 & 0 & \hat{Q}_{2} & 0 & 2 Y & 0 & 0 & 0 & 0 & \hat{Y} \\ 0 & 0 & 1 & 0 & 0 & 33 & \hat{Q}_{3} \\ k_{1} 1 & k_{2} & 0 & 0 & 0 & 0 & 0 & 0 & 0 & 0 & 0 & & \hat{P}_{1}^{*} \\ 0 & 0 & 0 & 1 & f_{1} & 0 & 0 & 0 & 0 & 0 & 0 & 0 & \hat{C}_{1} \\ 0 & 0 & 0 & 0 & 1 & f_{2} & 0 & 0 & h_{1} & 0 & h_{1} & 0 & \hat{R} \\ & & \hat{P}_{3}^{*} & 0 & 0 & 0 & h_{2} & f_{2} & 0 & \hat{A}^{*}\end{array}$

The comparative analysis can be executed by solving equation (13) on the basis of Cramer's rule.

\section{Comparative Analysis}

Analytical insights into the structural model are obtained by examining the comparative static properties of the model after solving equation (13). The quantity identity as defined in (4) reveals the connection between exports, domestic consumption, and imports, and hence can help us to trace the interactions and feedback effects between the three goods. This further reveals how the foreign content and the domestic market demand for the final products affect the response of exports to changes in the determinants. This is the main focus of our interests. 
The first task is to evaluate the effect of the changes in the exchange rate $(R)$ on the volume and price of exports. For this purpose, we assume that the rest of the exogenous variables in the model remain constant, and solve the matrix expression (13) to yield:

$$
\begin{aligned}
& \frac{\hat{P}_{1}^{*}}{\hat{R}}=\frac{h_{1} \varepsilon_{33}-k_{2} u_{2} s_{2} \eta}{\varepsilon_{33}-\eta} \\
& \frac{\hat{Q}_{1}}{\hat{R}}=\eta_{11} \frac{h_{1} \varepsilon_{33}-k_{2} u_{2} s_{2} \eta_{22}}{\varepsilon_{33}-\eta}
\end{aligned}
$$

where $=k_{1} u_{111}+k_{2} u_{2}{ }_{22}$, which is expected to be positive with the maintained hypothesis of negative own-price demand elasticity $\left(\eta_{11}\right.$ and $\left.\eta_{22}\right)$. Considering further an upward supply scheme $\left(\varepsilon_{33}>0\right)$, we can justify a positive (negative) response of the export price (volume) to changes in the exchange rate. Since the exchange rate is defined as the foreign currency value per China's currency, an increase in $R$ indicates an appreciation of the Chinese currency. The appreciated Chinese currency raises export price and reduces export quantity. However, the magnitudes of the above responsiveness are subject to the share of home content $\left(h_{l}\right)$. The inspection of equations (14) and (15) indicates that the higher the home content, the stronger the responsiveness of both export price and volume. Since $h_{l}=1-f_{l}$, it also means that the smaller the share of foreign content, the bigger the effect of changes in the Chinese currency value on exports. This is reasonable since in the price content of exported goods, only the processing cost is affected by the Chinese currency. A high home content, or in other words a small foreign content, means that a large portion of the export cost reacts to changes in the value of the Chinese currency.

In contrast to the export market, the appreciation of the RMB results in a decreased price and an increased volume in the home market (the derived equations are available 
upon request). The rationale behind this is that a smaller quantity of final products is exported to the world market, and thus more final products remain in the domestic market. The increased supply in the domestic market causes a decline in the domestic price. However, the net effect of the exchange rate on raw material imports is ambiguous depending on the relative responses between the export and the domestic market.

Turning to the processing cost, the changes in labor costs contained in the exported goods and domestically consumed goods $\left(C_{1}\right.$ or $\left.C_{2}\right)$ may correlate with each other. Recognizing the homogeneity of work added to final goods for exporting and home consumption in spite of the various degrees of processing, we can simply set $\hat{C}_{1}=\hat{C}_{2}=\hat{C}$. After further setting other exogenous variables to be constant, we solve the system to yield:

$$
\frac{\hat{P}_{1}}{\hat{C}}=\frac{h_{133}+\left(f_{1} f_{2}\right) k_{2} u_{222}}{33}
$$

With the maintained hypothesis of positive supply elasticity and negative demand elasticity, the effect of an increase in the labor cost on the export price is uncertain. In the case of $f_{1}<f_{2}$, which, as we have discussed, indicates highly processed exports, the export price would certainly increase following an increased unit labor cost, ceteris paribus. The larger the gap between the degrees of processing of exported and domestically consumed products, the more sensitive the export price with respect to changes in the labor cost.

To gain more insights into the effect of the labor cost, we assume the export supply to be fixed $\left(\varepsilon_{33}=0\right)$, which is a reasonable assumption for agricultural production, at least in 
the short run. We calculate the reduced-form elasticities of the exported and domestically consumed products with respect to the unit processing cost. This means:

$$
\begin{aligned}
& \frac{\hat{Q}_{1}}{\hat{C}}={ }_{11} \frac{\left(f_{1} f_{2}\right) k_{2} u_{222}}{\hat{Q}_{2}} \\
& \frac{\hat{C}}{\hat{C}} \eta_{22} \frac{-\left(f_{1}-f_{2}\right) k_{1} u_{1} \eta_{11}}{-\eta}
\end{aligned}
$$

Equations (17) and (18) show how the global demand and the home market change following a change in the Chinese labor cost, respectively. Again, in the normal case, when exports are more processed $\left(f_{1}<f_{2}\right)$, the sign of $\frac{\hat{Q}_{1}}{\hat{C}}$ is negative. This suggests that an increase in the unit cost would increase the export price and therefore reduce the export quantity. The magnitude of this reduction is directly related to the share of the home consumption $\left(k_{2}\right)$. Since $\varepsilon_{33}=0$, it suggests a constant import of the raw material in the short run and hence the fixed volume of final products, indicating that the reduction in the export volume exactly offsets the increase in the domestic demand $\left(\frac{\hat{Q}_{2}}{\hat{C}}>0\right)$. When the domestically consumed and exported products are processed to a close extent, the volume changes in both markets tend to be small. This is not out of expectation since the same degree of processing indicates the unchanged relative magnitudes between export price and home price, regardless of changes in the unit cost.

Following a similar logic, we can assess the impact of other determinants on China's exports. An increase in the world economic activity would raise the volume of China's exports. Growth in China's economic activity would lower the exports and promote the 
domestic demand. An improved production capacity of raw materials would raise both China's exports and the domestic demand levels.

\section{Parameterization}

The foregoing model is used in the case study of Chinese exports of ground fish, which is composed of cod, pollock, and haddock. China is the world's largest import-processing center of ground fish. Furthermore, as China produces almost no ground fish, it means that nearly all the exported ground fish products from China are made from imported raw fish, which makes the identification of the export data feasible.

To explore the determination of China's exports of ground fish, we need to set parameters in the structural model. Since no relevant parameters are estimated in the literature, we first estimate the demand and supply elasticities by using equations (1)-(3). For the empirical models, the variables are expressed in a logarithmic form, indicating that the parameters are explained as elasticities.

The empirical export demand model corresponding to equation (1) is specified after adding demand shifters and an error term $(U)$ :

$$
\log Q_{1}=\alpha_{0}+\alpha_{1} \log P_{1}^{*}+\alpha_{2} \log Y^{*}+\alpha_{3} \log P_{4}^{*}+U_{1}
$$

where $Q_{1}$ and $P_{1}^{*}$ are the volume and US dollar price of the ground fish products exported by China, respectively; the rest of the world's total imports of ground fish products act as a proxy for economic activity $\left(Y^{*}\right) ; P_{4}^{*}$ is the US dollar price of substitutes, i.e. ground fish products from countries with exception of China.

The domestic market demand for the processed fish is given as:

$$
\log Q_{2}={ }_{0}+{ }_{1} \log P_{2}+{ }_{2} \log Y+{ }_{3} \log P_{5}+U_{2}
$$


where $Q_{2}$ and $P_{2}$ are the quantity and price of domestically consumed ground fish, respectively; $Y$ is the total seafood products imported by China, a proxy for economic activity. Since the monthly domestic prices of tilapia are not available, we use the Chinese export prices of tilapia ( $P_{5}$ in the Chinese currency) to represent a substitute price in the domestic market.

Finally, the world export supply equation is specified as:

$$
\log Q_{3}={ }_{0}+{ }_{1} \log P_{3}^{*}+{ }_{2} \log A^{*}+{ }_{3} \log P_{6}^{*}+U_{3}
$$

where $Q_{3}$ and $P_{3}^{*}$ are the volume and US dollar price of ground fish imported by China, respectively; $Y^{*}$ is the production of ground fish in the major resource countries; and $P_{6}^{*}$ is the US dollar price of ground fish imported by the rest of the world.

Since Chinese data are often questioned by the FAO, trade partner countries' data on exports from and imports to China are used to obtain quantities and prices. For example, we use the US data on imports from China instead of China's data on exports to the US; similarly, we use the Norwegian export data instead of the Chinese import data. The adjusted differences between exports and imports are regarded as the domestic consumption. Since the domestic prices are unavailable, we use the price linkages to obtain a series to approximate the domestic price. ${ }^{5}$ After assuming seasonal changes in the production and global trade, the world annual ground fish production data are adjusted to obtain the quarterly production capacity. The sample period covers 1998:Q12011:Q4.

\footnotetext{
${ }^{5}$ From equation (5), the unit cost for exports $\left(C_{l}\right)$ can be derived. The unit costs for the two final goods are assumed to propitiate to the degree of processing $\left(C_{1}: C_{2}=0.85: 0.75\right.$, as we will discuss later). The solution of $C_{2}$ is then put to equation (6) to derive the domestic price series.
} 
Equations (19)-(21) were estimated as a system. The applied generalized moments method (GMM) approach employs a Newey-West covariance matrix to correct both for simultaneous equation bias and for cross-equation correlation in the error terms. Furthermore, in the system, the prices of final goods and raw materials are both endogenous, and hence are instrumented by their own lagged variables.

As shown in Table 1, the estimation results are satisfactory in that most of the coefficients are significant and have the correct signs. In the export equation, the price elasticity is -1.46 and the income elasticity is 0.84 . They are -1.93 and 0.97 , respectively, in the domestic demand equation. The price elasticity is more elastic in the domestic market than in the world market. This implies more substitutes for the ground fish in the Chinese table, which coincides with the property of an emerging market. The export supply elasticity is significant, with a value of 1.21 . However, the production capacity has no effect on the volume of ground fish exported to China. This is probably due to low variation in the global production of ground fish during the sample period.

*** Table $1 * * *$

The estimated elasticities are treated as "best-bet' values for simulation. For capacity elasticity, we take a value of 0.5 to incorporate the influence of rising capacity, as the quota of the major ground fish, like cod and pollock, was raised in 2012. Based on the survey data conducted by the project between UiT / the Arctic University of Norway and China Ocean University, Xie (2012) reports an input-output ratio of processed frozen fish fillets with a value of 0.75 . Therefore, we set $\mu_{1}$ to be $1.13(=1 / 0.75)$. As the products remaining in the domestic market are supposed to be less processed, we thus set 
$\mu_{2}$ to be $1.18(=1 / 0.85)$. To gauge the sensitivity of simulations, we also set some crucial parameters to be in a reasonable range later on.

\section{Simulation}

\subsection{Reduced-form elasticity}

The reduced-form elasticities are solved after replacing the "best-bet' structural parameters in the matrix equation (13). The results are reported in Table 2. Different from the elasticities, the reduced-form elasticities take account of the interactions between the export demand, the home consumption, and the import supply. Therefore, they are interpreted as the total effect.

\section{$* * *$ Table $2 * * *$}

Let us first consider the responsiveness of exports $\left(P_{1}\right.$ and $\left.Q_{1}\right)$. The total effect of a $1 \%$ increase in $R$ (appreciation of the Chinese currency) would be a $0.62 \%$ reduction in quantity $\left(\frac{\hat{Q}_{1}}{\hat{R}}\right)$ and a $0.42 \%$ rise in the price of products exported $\left(\frac{\hat{P}_{1}^{*}}{\hat{R}}\right)$. This indicates that the exchange rate strongly affects the Chinese exports of ground fish. The processing cost has a positive effect on the price and a negative effect on the volume of exports. As we discussed, this is not beyond expectation. The increased processing cost evidently causes the export price to increase, which reduces the world demand for the processed products. A $1 \%$ increase in the global economic activity and production capacity would raise the export quantity by $0.58 \%$ and $0.23 \%$, respectively. Rising economic activity is related to the demand expansion and leads to a $0.18 \%$ export price increase. However, an 
increase in the global production capacity lowers the price of raw materials and consequently reduces the export price by $0.19 \%$.

The quantity responses of the domestic demand $\left(Q_{2}\right)$ to changes in the exchange rate, the global economic activity, and the domestic economic activity have the inverse signs, compared with the corresponding sign of the export demand $\left(Q_{1}\right)$. This indicates redistribution effects on the spatial markets. This means that the high growth rate of Chinese economy relative to developed countries in the last decades and the appreciated Chinese RMB can partly explain an increasing volume of processed ground fish (especially Alaska pollock from Russia) remaining in China. According to our survey, these products are sold either as wrapped fillets in urban cities or as whole fish without heads in the rural areas of China.

Table 2 suggests that the export market is more sensitive to the changes in processing cost than the local market in terms of both price $(0.21 \%$ vs. $0.04 \%)$ and quantity $(-0.31 \%$ vs. $-0.08 \%$ ). This is attributed to the different degrees of processing between exported and domestically consumed goods, as might be expected.

For the same $1 \%$ increase, the domestic economic growth would raise the domestic demand by $0.72 \%$, while the global economic growth would only improve the global demand by $0.58 \%$. The domestic market also has a stronger response to changes in the production capacity of raw materials. The upshot is that the trade balance is likely to be reduced by the strengthened domestic demand for processing products as opposed to the dwindling global market. 


\subsection{Simulations}

In 2012 , China's currency appreciated by $2.7 \%, 1.4 \%$, and $10.3 \%$ with respect to the euro, the US dollar, and the Japanese yen, respectively. In the literature, the estimated degree of undervaluation of China's currency is about 10\% (Cheung et al., 2010). Accordingly, the average appreciation rate of $7 \%$ is treated as the "best-bet' value. Holz (2005) projects China's economic growth during 2005-15 to be in the range of 7-9\%. Since seafood is generally considered as a luxury in the Chinese market, we set the growth of domestic economic activity to be $10 \%$. Yang et al. (2010) document that, in the period 1998-2007, China's wage growth accelerated to $13.2 \%$. They suggest that the wage growth will stabilize to a moderate pace in the near future. Since the general wage index grew relatively faster than the processing costs, we assume a growth rate of $8 \%$ for the unit processing cost. Growth of the ground fish quota was observed in 2012 and 2013, so the production capacity of raw fish traded is assumed to grow by $5 \%$. The average annual growth rate of world seafood imports between 2000 and 2010 is 6.4\% (FAO, 2012). Noting the global economic recession during the last few years, we set the rest of the world economic activity growth at a $4 \%$ growth rate.

The individual and combined effects of the determinants are presented in Table 3.

\section{**** Table $3 * * *$}

The simulation results indicate that the appreciated Chinese currency has the strongest influence on the global market in terms of either price $(2.96 \%)$ or quantity (4.33\%). While the exchange rate contributes to most of the net changes in export quantity (-4.88\%), it only explains half of the net changes in export price (5.64\%). This reflects 
that other factors, especially the increased unit processing cost, also have a substantial influence on the export price.

In the domestic market, the negative impact of the exchange rate on the domestic price offsets the positive effects of other determinants, leading to an overall net reduction in the domestic price $(-3.43 \%)$. The great increase in quantity $(16.3 \%)$ is attributed to currency appreciation $(9.51 \%)$ as well as the expansion of the domestic economic activity $(7.23 \%)$. The huge increase in the home demand for the processed goods further offsets the negative effect of the global market, resulting in a net positive change in the quantity of raw material imported $(2.30 \%)$. Noting that the absolute net change in the import price $(-0.23 \%)$ is much smaller than the change in the import volume, the import value should increase and hence the Chinese trade surpluses should accordingly decrease.

\subsection{Sensitivity analysis}

The values of the foreign content $\left(f_{1}\right)$ and the domestic share $\left(k_{2}\right)$ in the structural model are fundamentally important to the final result of the simulation. Thus, we set the values of $f_{1}$ and $k_{2}$ in a range between the best-bet values to provide more reliable results.

For the foreign content, the previously set value is 0.61 . Considering the possible decline in or growth of the foreign content, we set alternative values of 0.4 and 0.80 . The other parameters and the percentage changes in the determinants are all the same as that presented in Table 3. The new simulated results are reported in Table 4. To make the analysis more readable, we only report the effect of the most important determinant, the exchange rate. At the same time, to keep a general picture, we also report the net effects of all the determinants in the table. 
The results suggest that the foreign content of processed products $\left(f_{1}\right)$ is pivotal in determining the effects of the exchange rate. The negative effect of the exchange rate on the quantity of the export products increases from $-3.20 \%$ to $-5.92 \%$ when $f_{1}$ decreases from the highest value of 0.8 to the lowest value of 0.4 . At the same time, the positive effect of the exchange rate on the price of the exported products increases about twice. A lower foreign content raises the share the processing cost (in the Chinese currency) out of the export price (in foreign currency). Therefore, the change in the value of the Chinese currency has a greater effect on the export price. An appreciation of $20 \%$ in China's currency has been proposed (Bergsten, 2010). If we set the change of $R$ in Table 4 to be $+20 \%$, the effect of the exchange rate will be even more significant. For example, if $f_{l}=$ 0.4 , the changes in the price and quantity of exports will be $11.6 \%$ and $-16.9 \%$, respectively. These values can be treated as the upper bound of the influence of Chinese currency appreciation on exports.

As we discussed before, there is a redistribution effect on the horizontal markets of those determinant factors. Table 4 shows that when the response of the export quantity becomes weak following a decline in the foreign content, the processed products consumed domestically are accordingly raised, leading to a moderate change in the raw materials imported by China. Compared with imports, exports are more sensitive to changes in the determinant factors. Again, this is because the effects of the determinants on imports are moderated by the responses of the domestic consumption.

Next we set the domestic market share $\left(k_{2}\right)$ to be 0.29 and 0.60 , alternatively, and focus on the impact of the unit processing cost. Remember, $k_{2}=0.40$ is the value 
originally set. To facilitate the examination of the redistribution effect of the determinants, as shown in equations (17) and (18), here we set the import supply elasticity equal to zero. The simulation results are presented in Table 5.

$* * *$ Table $5 * * *$

In all scenarios, the increased unit cost raises the export price and reduces the export quantity. Since the exported products are processed to a higher level than the domestically consumed products, the increased unit cost raises the relative price of the processed products in the global market, and hence lowers the supply. The shift in the processed products from the global market to the domestic market results in a lower price and an increased consumption in the home market given the fixed volume of the raw materials imported. This is related to the assumed Leontief technology in production, which causes the unchanged total supply of final products given the fixed volume of the raw materials imported.

An increase in the domestic market share $\left(k_{2}\right)$ accelerates the responsiveness of the price and quantity of exports with respect to changes in the unit processing cost. When the unit cost grows by $8 \%$, the simulated price changes range between $0.66 \%$ and $1.15 \%$, with the lower and the upper bounds corresponding to $k_{2}=0.29$ and 0.60 , respectively. The sensitivity of other determinants' roles to the share of domestic consumption is also evidenced in the combined effects. They raise the export price by $5.53 \%$ and $9.26 \%$, corresponding to $k_{2}=0.29$ and 0.60 . 


\section{Concluding Remarks}

The basic theme of this paper is that the share of foreign content in Chinese exports can have an important bearing on the evaluation of trade determinants. The increased export price due to either the revaluated Chinese currency or the rising labor cost may undercut the comparative advantage of Chinese products in the global markets. However, as a large number of Chinese exports comprise both foreign and home inputs, the exact extent to which the Chinese competitiveness is affected due to the revaluated Chinese currency or the rising labor cost is subject to the share of foreign content in exports.

The foregoing proposition is first explored in a structural model that is composed of the world and home demands for the processed products, the import supply of raw materials, and the price linkages between the raw material market and the two final markets. The comparative analysis reveals a positive relationship between the share of foreign content and the export price changes due to the appreciated Chinese currency and/or the rising labor cost. Furthermore, the impacts of the processing cost on the foreign and home markets are subject to the processing level of exports relative to homeconsumed goods. If those two goods are processed to the same degree from the imported raw material, the impact of changes in the processing cost tends to be minimal.

The empirical case discussed is the ground fish trade. The derived reduced-form elasticities indicate that the exchange rate and unit cost are the main factors determining the ground fish trade, although the world and home economy activities also play a role in export price and quantity. Taking the assumed growth rate of each determinant into account, the simulation results suggest an increased influence of the home economy due to its high growth rate. The results of the sensitivity analysis indicate that the influence of 
the exchange rate is substantially subject to the share of foreign content of the processed ground fish. A high amount of foreign content means that the processing cost (in Chinese currency) accounts for a low share in the export price and hence a marginal impact of the overvalued Chinese currency on export price. In the scenario in which the supply of ground fish used as raw materials is fixed, the simulation results reveal the redistribution effect of the determinant factors on the foreign and home markets. When the domestic market share increases, changes in individual determinants like the unit cost have a stronger effect in the ground fish export market. Given the expected growth rates of the Chinese and the world economy, the influence of the relative income (at home versus abroad) is more likely to prevail. At the same time, the increased home demand for highquality processed tradables and the high share of foreign content lead to a weak impact of changes in the exchange rate and unit cost on the relative price of the exported and domestically consumed final goods.

There is a lot of argument about the impact of exchange rate on China's exports. However, as Zhang and Wang (2007) note: “... it is therefore advisable to caution against overplaying the causation from exchange rate movements to changes in the trade balance'. One reason of the overstatement of the impact of exchange rate on trade flows is the foreign content in China's exports. A higher foreign content leads to a smaller impact of the appreciated currency on export price. This is verified by our comparative analysis of the structural model and the empirical findings of our case study: the ground fish. China plays a substantial influence on the global seafood market, especially for processed seafood products (Zhang et al., 2014). For example, although China do not produce salmon, China is currently the major supplier of fresh fillet salmon in the US 
market only after Chile (Xie and Zhang, 2014). Thus, how to apply our methodology to salmon and other processed fish is an issue for further research. This kind of studies can shed insight on trade pattern of China's seafood and the global seafood market as well. 


\section{References}

Álvarez, R. and Claro, S. (2009). 'David versus goliath: the impact of Chinese competition on developing countries.' World Development, Vol. 37, No. 3, pp.560571.

Amiti, M. and Freund, C. (2010). 'The anatomy of china's export growth.' In China's Growing Role in World Trade (pp. 35-56). University of Chicago Press.

BAAK, S. (2008). 'The bilateral real exchange rates and trade between China and the U.S.' China Economic Review, Vol. 19, pp.117-127.

Bergsten, C.F. (2010). 'Correcting the Chinese exchange rate.' Testimony before the Hearing on China's Exchange Rate Policy, Committee on Ways and Means, US House of Representatives.

Cheung, Y.W., Chinn, M.D. and Fujii, E. (2010). 'China's current account and exchange rate.' In China's Growing Role in World Trade (pp. 231-271). University of Chicago Press.

Dhoubhadel, S.P., Azzam, A.M. and Stockton, M.C. (2015). 'The impact of biofuels policy and drought on the US grain and livestock markets.' Journal of Agricultural and Applied Economics, Vol. 47, No. 01, pp.77-103.

FAO [Food and Agricultural Organization of the United Nations]. (2012). The state of the world fisheries and aquaculture. Rome: Food and Agriculture Organization of the United Nations.

Holz, C.A. (2008). 'China's economic growth 1978-2025: what we know today about China's economic growth tomorrow.' World Development, Vol. 36, No. 10, pp.1665-1691.

Kinnucan, H.W. and Myrland, Ø. (2005). 'Effects of income growth and tariffs on the world salmon market.' Applied economics, Vol. 37, No. 17, pp. 1967-1978.

Koopman, R., Wang, Z. and Wei, S.J. (2008). 'How much of Chinese exports is really made in China? Assessing domestic value-added when processing trade is pervasive.' National Bureau of Economic Research, No. w14109. 
Luckstead, J. and Devadoss, S. (2016). 'Impacts of the transatlantic trade and investment partnership on processed food trade under monopolistic competition and firm heterogeneity.' American Journal of Agricultural Economics, Vol. 98, No. 5, pp.1389-1402

Manova, K. and Zhang, Z. (2012). 'Export prices across firms and destinations.' The Quarterly Journal of Economics, Vol. 127, No. 1, pp.379-436.

Rodrik, D. (2010). 'Making room for China in the world economy.' American Economic Review, Vol. 100, No. 2, pp.89-93.

Schott, P.K. (2007). 'The relative sophistication of Chinese exports.' Economic Policy, Vol. 23, No. 53, pp.5-49.

The New York Time. (2010). The long view of china's currency. September 21.

Wang, Z. (2003). 'The impact of China's WTO accession on patterns of world trade.' Journal of Policy Modeling, Vol. 25, No. 1, pp.1-41.

Wang, Y., Hui, X. and Soofi, A.S. (2007). 'Estimating renminbi (RMB) equilibrium exchange rate.' Journal of Policy Modeling, Vol. 29, pp.417-429.

Yang, D.T., Chen, V.W. and Monarch, R. (2010). 'Rising wages: has china lost its global labor advantage?' Pacific Economic Review, Vol. 15, No. 4, pp.482-504.

Xing, Y. (2012). 'Processing trade, exchange rates and china's bilateral trade balances.' Journal of Asian Economics, Vol. 23, pp.540-547.

Xie, J. (2012). China-supply, processing and market outlook, presentation in the Norwegian cod conference, November 15, 2012, Troms $\varnothing$, Norway. http://www.seafood.no/Nyheter-ogmedia/Konferansekalender/Torskefiskkonferansen-2012 (accessed December 18 2015).

Xie, J. and Zhang, D. (2014). 'Imperfect Competition and Structural Changes in the U.S. Salmon Import Market.' Marine Resource Economics, Vol. 29, No. 4, pp.375-389. 
$\mathrm{Xu}$, B., and Lu, J. (2009). 'Foreign direct investment, processing trade, and the sophistication of china's exports.' China Economic Review Vol. 20, No. 3, pp. 425439.

Zhang, D., and Kinnucan, H.W. (2014). 'Exchange rate volatility and US import demand for salmon'. Marine Resource Economics, Vol. 29, No. 4, pp. 411-430.

Zhang, D., Tveterås, R. and Lien, K. (2014). 'China's impact on global seafood markets.' Aquaculture Economics \& Management, Vol. 18, No. 2, pp.101-119.

Zhang, D., Zheng, Y. (2016). 'The role of price risk in China's agricultural and fisheries exports to the US.' Applied Economics, 48(41): 3944-3960.

Zhang J.H., van Witteloostuijn, A. and Elhorst, J.P. (2011). 'China's politics and bilateral trade linkages.' Asian Journal of Political Science, Vol. 19, No. 1, pp. 25-47.

Zhang, Y. and Wan, G. (2007). 'What accounts for China's trade balance dynamics?' Journal of Policy Modeling, Vol. 29, No. 6, pp.821-837. 
Table 1. Estimation results

$$
\begin{aligned}
& \text { Export demand equation for ground fish } \\
& \log Q_{1}=4.8961 .456 \log P_{1}^{*}+0.841 \log Y^{*}+0.096 \log P_{4}^{*} \\
& (0.698)(0.054) \quad(0.047) \quad(0.037) \\
& \mathrm{R}^{2}=.926 p \text {-value }<0.001
\end{aligned}
$$

Domestic demand equation for ground fish

$$
\begin{gathered}
\log Q_{2}=8.575 \quad 1.931 \log P_{2}+0.974 \log Y+0.337 \log P_{5} \\
(1.008)(0.204) \quad(0.111) \\
\mathrm{R}^{2}=.413 p \text {-value }<0.001
\end{gathered}
$$

Supply equation for ground fish

$$
\begin{aligned}
& \log Q_{3}= 11.315+1.214 \log P_{3}^{*}+0.001 \log A^{*} \quad 0.228 \log P_{6}^{*} \\
&(0.412)(0.028) \quad(0.059) \\
& \mathrm{R}^{2}=.522 p \text {-value }<0.001
\end{aligned}
$$

Note: Numbers in parentheses are standard errors. 
Table 2. Reduced-form elasticities

\begin{tabular}{cccccc}
\hline Endogenous & \multicolumn{5}{c}{ Exogenous Variables (Determinants) } \\
\cline { 2 - 6 } Variables & $\hat{Y}^{*}$ & $\hat{Y}$ & $\hat{C}$ & $\hat{R}$ & $\hat{A}^{*}$ \\
\hline$\hat{P}_{1}^{*}$ & 0.18 & 0.10 & 0.21 & 0.42 & -0.16 \\
$\hat{P}_{2}$ & 0.22 & 0.13 & 0.04 & -0.70 & -0.19 \\
$\hat{P}_{3}^{*}$ & 0.29 & 0.17 & -0.28 & 0.06 & -0.26 \\
$\hat{Q}_{1}$ & 0.58 & -0.15 & -0.31 & -0.62 & 0.23 \\
$\hat{Q}_{2}$ & -0.42 & 0.72 & -0.08 & 1.36 & 0.38 \\
$\hat{Q}_{3}$ & 0.24 & 0.14 & -0.23 & 0.05 & 0.28 \\
\hline
\end{tabular}


Table 3. Simulation results

\begin{tabular}{ccccccc}
\hline \multirow{2}{*}{$\begin{array}{c}\text { Endogenous } \\
\text { Variables }\end{array}$} & \multicolumn{5}{c}{ Changes in Exogenous Variables (Determinants) } \\
\cline { 2 - 6 }$\hat{Y}^{*}(+4 \%)$ & $\hat{Y}_{(+10 \%)}$ & $\hat{C}_{(+8 \%)}$ & $\hat{R}_{(+7 \%)}$ & $\hat{A}^{*}(+5 \%)$ & Sum \\
\hline$\hat{P}_{1}^{*}(\%)$ & 0.71 & 1.05 & 1.72 & 2.96 & -0.80 & 5.64 \\
$\hat{P}_{2}(\%)$ & 0.87 & 1.28 & 0.33 & -4.93 & -0.97 & -3.43 \\
$\hat{P}_{3}^{*}(\%)$ & 1.15 & 1.71 & -2.23 & 0.43 & -1.30 & -0.23 \\
$\hat{Q}_{1}(\%)$ & 2.32 & -1.53 & -2.51 & -4.33 & 1.17 & -4.88 \\
$\hat{Q}_{2}(\%)$ & -1.67 & 7.23 & -0.63 & 9.51 & 1.88 & 16.3 \\
$\hat{Q}_{3}(\%)$ & 0.97 & 1.44 & -1.87 & 0.36 & 1.41 & 2.30 \\
\hline
\end{tabular}


Table 4. Sensitive analysis by altering share of foreign content

\begin{tabular}{ccccccccc}
\hline \multirow{2}{*}{$\begin{array}{c}\text { Endogenous } \\
\text { variables }\end{array}$} & \multicolumn{2}{c}{$f_{l}=0.40$} & & \multicolumn{2}{c}{$f_{l}=0.61$} & & \multicolumn{2}{c}{$f_{l}=0.80$} \\
\cline { 2 - 3 } \cline { 8 - 9 } \cline { 8 - 9 } & $\hat{R}_{(+7 \%)}$ & Sum & & $\hat{R}_{(+7 \%)}$ & Sum & & $\hat{R}_{(+7 \%)}$ & Sum \\
\hline$\hat{P}_{1}^{*}(\%)$ & 4.06 & 8.17 & & 2.96 & 5.64 & & 2.19 & 3.85 \\
$\hat{P}_{2}(\%)$ & -5.52 & -4.80 & & -4.93 & -3.43 & & -4.51 & -2.45 \\
$\hat{P}_{3}^{*}(\%)$ & -0.36 & -2.07 & & 0.43 & -0.23 & & 0.99 & 1.06 \\
$\hat{Q}_{1}(\%)$ & -5.92 & -8.57 & & -4.33 & -4.88 & & -3.20 & -2.26 \\
$\hat{Q}_{2}(\%)$ & 10.66 & 19.0 & & 9.51 & 16.3 & & 8.70 & 14.4 \\
$\hat{Q}_{3}(\%)$ & -0.30 & 0.76 & & 0.36 & 2.30 & & 0.83 & 3.39 \\
\hline
\end{tabular}


Table 5. Sensitive analysis by altering the share of some consumption

\begin{tabular}{ccccccccc}
\hline \multirow{2}{*}{$\begin{array}{c}\text { Endogenous } \\
\text { variables }\end{array}$} & \multicolumn{2}{c}{$k_{2}=0.29$} & & \multicolumn{2}{c}{$k_{2}=0.40$} & & \multicolumn{2}{c}{$k_{2}=0.60$} \\
\cline { 2 - 3 } & $\hat{C}$ & Sum & & $\begin{array}{c}\hat{C} \\
(+8 \%)\end{array}$ & Sum & & $\begin{array}{c}\hat{C} \\
(+8 \%)\end{array}$ & Sum \\
\hline$\hat{P}_{1}^{*}(\%)$ & 0.66 & 5.53 & & 0.85 & 7.02 & & 1.15 & 9.26 \\
$\hat{P}_{2}(\%)$ & -0.97 & -3.56 & & -0.73 & -1.74 & & -0.36 & 1.00 \\
$\hat{P}_{3}^{*}(\%)$ & -3.96 & -0.42 & & -3.63 & 2.01 & & -3.15 & 5.66 \\
$\hat{Q}_{1}(\%)$ & -0.96 & -4.71 & & -1.24 & -6.89 & & -1.68 & -10.2 \\
$\hat{Q}_{2}(\%)$ & 1.87 & 16.57 & & 1.40 & 13.06 & & 0.70 & 7.78 \\
$\hat{Q}_{3}(\%)$ & 0.00 & 2.50 & & 0.00 & 2.50 & & 0.00 & 2.50 \\
\hline
\end{tabular}

